\title{
Patterns of tree diversity in response to logging in Algonquin Provincial Park
}

\author{
Brittany Jones*, Olivia Molenda*, Colin Hayward*, Mark D'Aguiar, Nathan \\ Miller, Leslie Rye, Karl Cottenie**
}

\author{
* These 3 undergraduate students contributed equally to the manuscript. \\ **This study was conducted under the supervision of Professor Karl Cottenie \\ Department of Integrative Biology, College of Biological Science \\ University of Guelph
}

\begin{abstract}
The acceleration of human disturbance on natural systems necessitates the understanding of the effects of disturbance on species diversity, in order to mitigate its impacts. The Intermediate Disturbance Hypothesis (IDH) provides a general framework for predicting how these effects will unfold, centered on the premise that diversity will be maximized at intermediate levels of disturbance, or after an intermediate amount of time has passed since the last disturbance. We investigated the impact of disturbance by logging in Algonquin Provincial Park, ON, Canada, on tree species diversity. We sampled 7 sites, with known times since the last logging event, ranging between 4 and 149 years. We found that species richness and diversity indeed peaked at an intermediate disturbance regime of approximately 80 years since logging. We also found that this maximum diversity was caused by a combination of early, pioneer, postpioneer, sub-climax, and climax species. Our experiment shows that IDH is applicable to the mixed forests of Algonquin, and therefore, provided that sites are logged after a suitable amount of time has passed, it is possible to harvest trees and maintain diversity.
\end{abstract}

U nderstanding the mechanisms controlling diversity has become increasingly important as the rate of decline in global species continues to accelerate [1,2,3]. Maintaining high biodiversity is economically and socially valuable because it increases the functionality and resilience of ecosystems [4]. Historically, the earth has experienced five massive extinctions [5]: Current extinction rates are just as high, and humans have been solely responsible for $5-20 \%$ of current species extinctions through human-induced habitat disturbances $[5,6]$.

One major theoretical framework to study the effects of disturbances, human or natural, on ecosystems, is the Intermediate Disturbance Hypothesis (IDH). The IDH states that at intermediate levels of disturbance, diversity is maximal, either after an intermediate amount of time has passed since the last disturbance or when the disturbance (ie. fire) is of intermediate intensity [7,8,9,10,11]. Chase and Leibold [12] hypothesized two potential causal mechanisms for this relationship. On the one hand, sites experiencing intermediate levels of disturbance are expected to be in the post-pioneer to sub-climax stage, where dominance by one species gives way to dominance by another [8,12]. This allows competitive, climax, species and disturbance-tolerant, or pioneer, species to coexist locally for a period of time as they transition through the stage, resulting in maximum diversity at intermediate disturbance levels, at a local scale $[8,12]$. Furthermore, intermediate disturbance could result in maximum diversity at a regional scale, because different sites within a region may have been disturbed at different times [12]. The time since disturbance in each locality would be highly divergent and therefore each site may be in a different successional stage [12]. When all these sites are sampled within a region, diversity would be high [12].

This hypothesis has been applied to various ecosystems and organismal groups. However, a quantitative review of the published effects of disturbance on diversity found that the patterns predicted by the IDH [8] are not present in all disturbance situations. To explain this discrepancy, follow-up ecological theory suggested that the IDH is applicable when environmental variability is strongly correlated with organism persistence [13], such as in forest systems. Forests have thus been extensively used to test the intermediate disturbance hypothesis to various degrees $[8,11,14,15,16,17,18,19]$. These tests covered both temperate [20] and tropical environments [18], and time spans covering 10 years [16] to 300 years [20]. 
Since logging is a major human disturbance affecting forests world-wide, we suggest that the forests in Algonquin Provincial Park, in Ontario, Canada, provide ideal locations to study the effects of logging on diversity. Algonquin has a rich logging history dating back to the 1800s, even though the park was not established until 1893 [21]. Spatial and temporal restrictions on logging have been increased by park management since the parks establishment [21], and as a result, different areas of the park have been logged at different times, producing a wide range of recovering logged sites. This provides an excellent location for the study of the intermediate disturbance hypothesis. Currently, the first objective in establishing and managing a provincial park, is [22]:

"To permanently protect representative ecosystems, biodiversity and provincially significant elements of Ontario's natural and cultural heritage and to manage these areas to ensure that ecological integrity is maintained."

Where ecological integrity means [23]:

"with respect to a park, a condition that is determined to be characteristic of its natural region and likely to persist, including abiotic components and the composition and abundance of native species and biological communities, rates of change and supporting processes."

Therefore, knowledge on the effects of logging regimes on tree diversity is a crucial step in maintaining the ecological integrity of this system.

We hypothesize that tree diversity in Algonquin will peak after an intermediate amount of time has passed since the last logging disturbance, as predicted by the intermediate disturbance hypothesis. We chose to measure disturbance

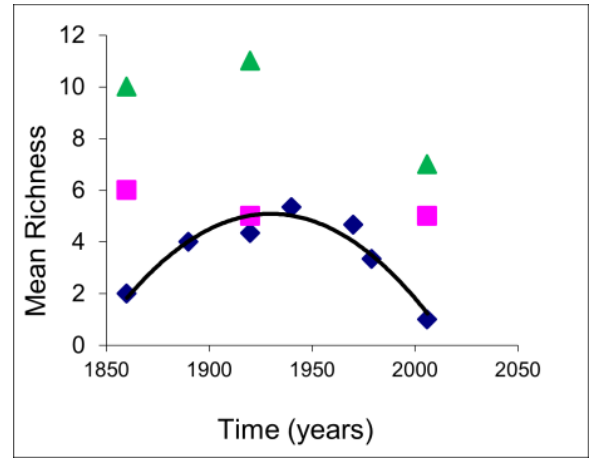

Figure 1 Mean species richness from 7 experimental plots in Algonquin Provincial Park over 150 year time period. The blue points represent the $10 \mathrm{~m} \times 10 \mathrm{~m}$ plots, the pink points are the $20 \mathrm{~m} \times 20 \mathrm{~m}$ plots, and the green points are the $40 \mathrm{~m} \times 40 \mathrm{~m}$ plots. The trend line is shown for the $10 \mathrm{~m} \times 10 \mathrm{~m}$ plots. levels as time passed since logging, because we do not know the type or frequency of logging on these sites but we do know when they were last logged. Time since the last logging date will be used as a proxy for frequency since high frequency should correlate with a short time to last disturbance, in this case logging [10]. Diversity was measured with two common metrics: Species richness, which refers to the number of different species found, and the Shannon-Weiner Diversity index (SWD), which incorporates richness and the proportion of individuals relative to each other [10]. SWD is a measure of species richness, but modified by the relative abundances of the different species [10], to avoid the potential biases of including rare species in the calculation of species richness.

We also differentiated between the two different mechanisms affecting the presence of IDH in this forest ecosystem. If disturbance is on a regional scale then local, small-scale, sampling would not be sufficient to capture landscape level diversity changes. If, on the other hand, disturbance is on a local scale, it should be detectable at small scales. Moreover, if the IDH is the result of local scale disturbance, then we predict that the tree species present in these intermediate disturbance conditions, with maximum species richness, will be a combination of pioneer and climax tree species, with some intermediate successional specialists present as well.

\section{RESULTS}

Time since logging was associated with both mean richness (Figure 1) and SWD (Figure 2) unimodally in the $10 \mathrm{~m} \times 10 \mathrm{~m}$ plots, as predicted by the IDH. In both cases, diversity was highest after an intermediate period of time, of approximately 80 years, had passed. However, these unimodal relationships between species diversity and time since logging disappeared in the larger quadrates (Figure 1 and Figure 2), which tested the local versus regional mechanism of IDH.

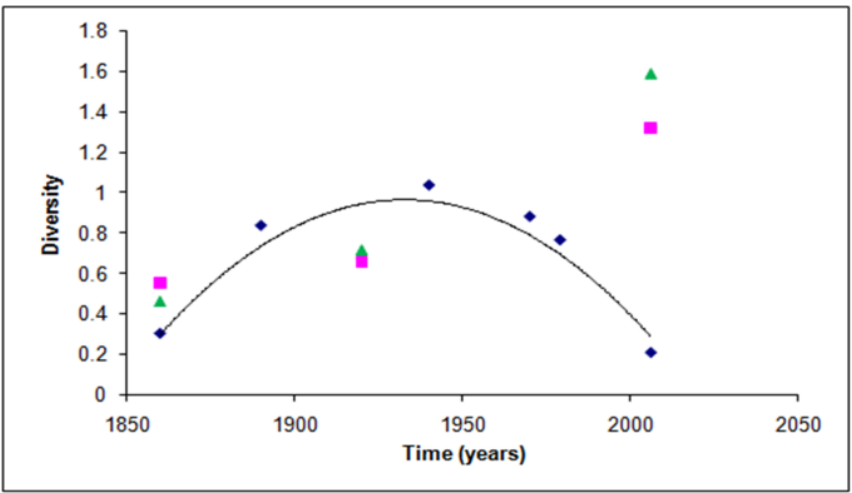

Figure 2 Diversity from 7 experimental plots in Algonquin Provincial Park over 150 year time period. The blue points represent the $10 \mathrm{~m}$ $x 10 \mathrm{~m}$ plots, the pink points represent the $20 \mathrm{~m} \times 20 \mathrm{~m}$ plots, and the green points represent the $40 \mathrm{~m} \times 40 \mathrm{~m}$ plots. The trend line is shown for the $10 \mathrm{~m} \times 10 \mathrm{~m}$ plots. 
Table $1 \mathrm{R}^{2}$, adjusted $\mathrm{R}^{2}$, Year ${ }^{2}$, and $\mathrm{p}$-values, for species richness and the Shannon-Weiner diversity index.

\begin{tabular}{ccccc}
\hline $\begin{array}{c}\text { Dependent } \\
\text { variable }\end{array}$ & $\mathbf{R}^{2}$ & $\begin{array}{c}\text { Adjusted } \\
\mathbf{R}^{2}\end{array}$ & Year $^{2}$ & $\begin{array}{c}\text { P-value of the } \\
\text { Year } \\
\text { coefficient }\end{array}$ \\
\hline Species Richness & 0.9225 & 0.8856 & 0.0023 & 0.0058 \\
Shannon-Weiner & 0.8054 & 0.7035 & 0.0157 & 0.0391 \\
\hline
\end{tabular}

A multiple regression analysis (Table 1) indicated that $88.56 \%$ of the variation in richness and $70.35 \%$ of the variation in SWD was accounted for by the time since disturbance. The regression analysis also yielded a significant Year $^{2}$ value for both species richness and diversity, the formal test of the IDH prediction.

\section{Multivariate analysis}

In addition to explaining species diversity patterns, the time since logging also explained a significant amount of variation in tree abundances $\left(\mathrm{F}_{(1,25)}=2.13\right.$, $\mathrm{p}$-value $\left.=0.04\right)$. The old sites (or climax community) were characterized by high abundances of sugar maple, the young sites by red maple, white birch and yellow birch (pioneer community), and the intermediate sites had a combination of both types of communities, in addition to other species such as balsam fir (Figure 3), as predicted by the local mechanisms resulting in IDH. Figure 3 also indicates that the age of site 5, at Sunday Lake, may not have been correctly determined, since these plots were very similar in tree composition to the oldest sites that were sampled at Brewer Lake (site 1). Moreover, the larger sampling plots had similar species compositions to the smaller sampling plots within each site, which corresponds to predictions of the local disturbance model of the IDH.

\section{DISCUSSION}

We tested the applicability of the intermediate disturbance hypothesis in the forests of Algonquin Provincial Park. Species richness, which is based on the number of species coexisting in a community, followed a pattern predicted by the IDH [25]. Maximum tree species richness occurs after an intermediate amount of time since logging (80 years), supporting the IDH hypothesis.

These results are consistent with previous studies of tree communities that supported the IDH $[11,16,17,18]$. Bongers et al. [11] examined 2504 forest plots and showed that species density displayed the typical unimodal relationship to disturbance in all cases. Another study by Guo [26] found that diversity first increased and then declined, in accordance with the IDH, in $68 \%$ of their study sites. The main mechanisms for this positive effect on species richness following disturbance is the resetting of the community to an earlier successional stage, therefore allowing more species to invade $[8,11,14,16,17,18]$.

Many studies have shown that when disturbance is measured as length of time since the last disturbance, the data were more highly correlated than when it is measured as intensity [8]. Mackey and Currie [8] also hypothesized that the unimodal relationship between disturbance and diversity should be higher in plant communities than animal ones, because plants are competing for space and are not mobile. Consequently, many authors have shown that the IDH does manifest itself in forests $[16,17,18]$.

As the IDH has two spatial forms in which it can manifest, it is important to discern which is present in the mixed forests of Algonquin Provincial Park. Evidence from this study suggests that the IDH follows the local model (Figure 3) [12]. This is demonstrated, in the $10 \mathrm{~m} \times 10 \mathrm{~m}$ plots, by highest diversity being observed at sites where an intermediate amount of time has passed since the last disturbance.

When we increased the sampling area from $100 \mathrm{~m}^{2}$ to $400 \mathrm{~m}^{2}$ and $1600 \mathrm{~m}^{2}$, we captured more species, as expected. If our results supported the regional model of IDH, the curves would become more peaked as a greater number of species were found in the larger plots. In contrast, the results of this study demonstrated a linear biodiversity curve in the larger sampled plots. The plots displaying the highest levels of species richness, in the smallest plots, contained a combination of both pioneer and climax species. This is another prediction of the mechanisms involved in the IDH at a local scale.

The multivariate analysis showed that time since logging explained a large and significant amount of the variation in tree abundances, as can be seen by the distribution in Figure 3. These results closely correspond to the findings of Martin [20], who examined the stages of succession in the forests of Algonquin Provincial Park. He indicated the order of establishment and subsequent removal of tree species from the forests as they age. The order of succession moves from pioneer to post-pioneer, followed by sub-climax and then climax. Colonizers or pioneer species are species which are capable of invading a recently disturbed site [20]. In Algonquin Provincial Park, Populus tremuloides (trembling aspen), Betual papyrifera (white birch) and Acer rubrum (red maple) readily colonize disturbed sites [20]. Both red maple and white birch were found to be characteristic of the younger sites sampled in the current study, as well as yellow birch. Post-pioneer species in Algonquin consist of either Abies balsamea (balsam fir) and Picea spp. (spruce) or Pinus strobes (white pine) with $P$. resinosa (red pine) [20]. The pioneer species serve as facilitators changing the micro-climate such that it becomes favourable to post-pioneer species [27]. These species were typically found in the intermediate sites sampled in the current study. The sub-climax successional stage in Algonquin can be very long, lasting up to 800 years [20]. Sub-climax species are good competitors which over many generations have the ability to exclude all other species. Such species in Algonquin are Acer saccharum (sugar maple), 


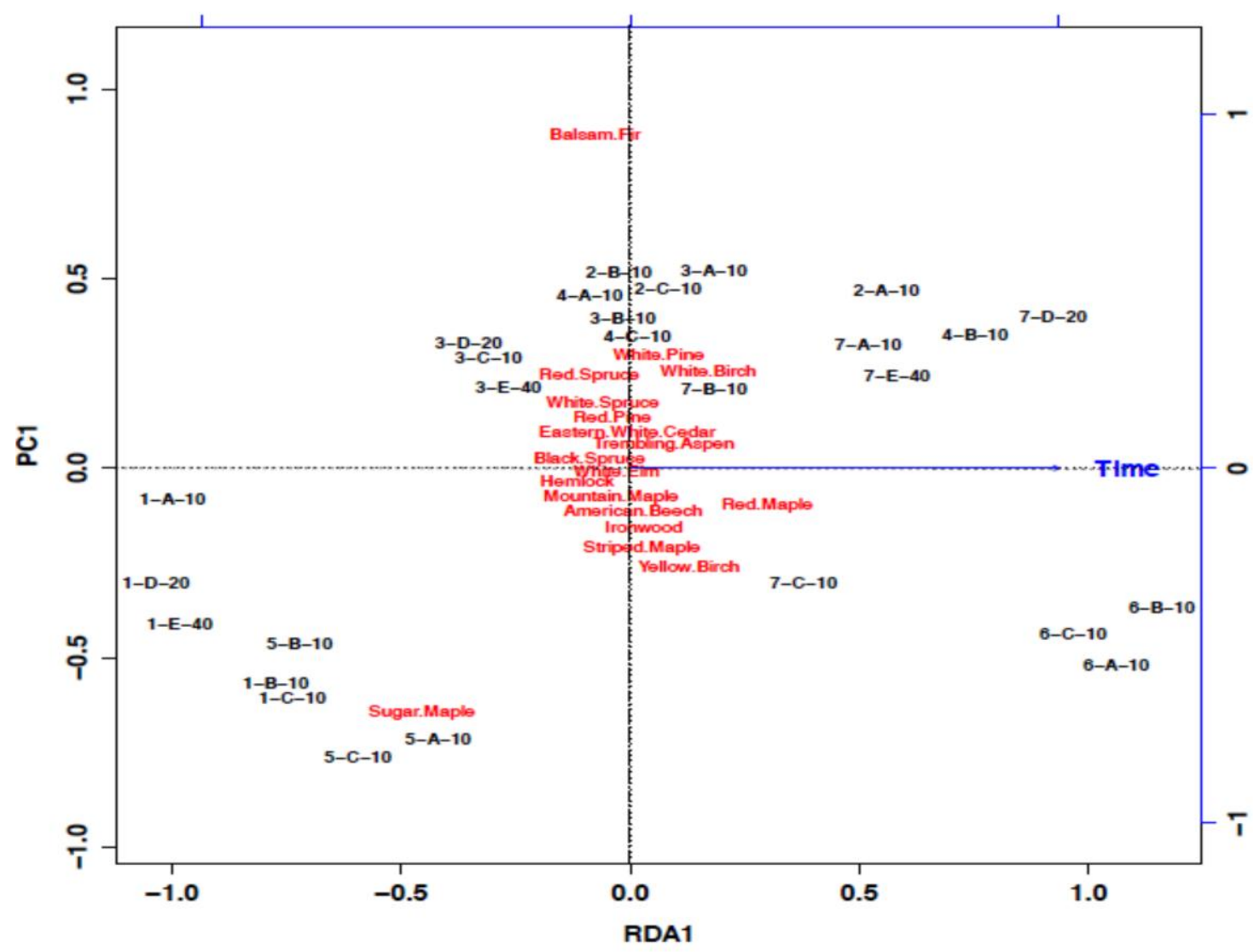

Figure 3 Results of the RDA analysis with tree abundances as the dependent matrix and time as the independent variable. Since RDA only computed a single RDA axis, it was plotted versus the first Principal Component Axis, to visualize the general patterns in the tree abundances. The letter codes indicate the different sites, with the first number the site, the letter is the replicate, and the last number the size of the replicate (quadrates with $10 \mathrm{~m}, 20 \mathrm{~m}$, or $40 \mathrm{~m}$ sides). 1 represents the oldest site that was sampled, Brewer Lake -1860 , and 7 represents the youngest site at the WRS - 2006. The red names indicate the positions of the tree variables, and the blue variable indicates the effect of the time since logging.

Betula lutea (sweet birch) and Fagus grandifolia (American beech). Sugar maple was characteristic of the oldest site in this study (1860), as well as in site 5 at Sunday Lake; which is one of the main indicators that this site is much older than originally thought. Climax species in Algonquin consist of Tsuga canadensis (hemlock) and Thuja occidentalis (cedar), which live in dry climates. These species are present from the post-pioneer stage but do not dominate for many years; ultimately they out compete sub-climax species. Both of these species were present in the intermediately aged plots, however, with the sub-climax stage being able to persist for such a long period of time, these species were not found to be dominant in any of the plots in the current study, which only covered 150 years.

This model of succession is known as the facilitation model, where only certain pioneer species can colonize a recently disturbed site [28]. In the other models of succession, tolerance and inhibition, any species that arrives on the site may be able to colonize it, even if these species are usually present at later stages [28]. Although these other successional models are possible, Martin [20] demonstrated that it is the facilitation model that acts in the forests of Algonquin Provincial Park.

As is the case of all field studies, limitations to sampling may affect the results. Our results, for instance, suggest that site 5, at Sunday Lake, was aged incorrectly. We estimated that Sunday Lake had been logged around 1970, as it contained clearly cut stumps with some degradation due to rot. Contrary to this, Figure 3 suggests that species composition at the site at Sunday Lake is actually much more similar to site 1, at Brewer Lake. Both sites contained high numbers of Sugar Maple, indicative of a sub-climax forest. Alternative explanations could be similar cutting techniques or site conditions, independent of the disturbance regime. Given the location of site 5 on Figure 3, with reference to those around it, Sunday Lake could have been logged over 
100 years ago; however this is still a rough estimate. We would need to return to the site in order to collect samples, to make a more accurate prediction of the time since logging.

Additional sources of error may have occurred at the corridor site at The Algonquin Wildlife Research Station (WRS). The area that was cut along the corridor was directly beneath the hydro lines and was no more than $5 \mathrm{~m}$ wide in some areas. With only 5 metres of width available for sampling, it was impossible to maintain the same dimensions that were used in the other study sites. In order to keep the same area of $1600 \mathrm{~m}^{2}$ for the upscale $(40 \mathrm{~m} \mathrm{X} 40 \mathrm{~m})$, the dimensions had to be $5 \mathrm{~m}$ X $320 \mathrm{~m}$. As patch size decreases, via smaller width in this case, the amount of influence originating from outside the habitat increases; these are known as edge effects [25]. Previous studies have shown that dispersal into open areas occurs from both nearby trees [29], as well as animal carriers, such as birds [30]. Greene and Johnson [29] suggest that the greatest contributor of seeds to a clearing is from those trees surrounding it. With a greater area of the plot at the WRS in contact with surrounding trees, many more individuals would have provided seeds for recruitment into the sampled area; therefore tree species that would normally take a lot longer to disperse into the area would have found it easier to become established in the corridor. The edge effects were greatly increased in the corridor and could have contributed to a greater number of species being found there.

Type of logging could also have confounded some of the data, as the type of logging conducted in the park has changed over time. Starting in approximately 1830, logging in Algonquin Provincial Park was predominately done on pine and then expanded to include spruce [31]. With declining availability and new demand, the selected species included yellow birch, hemlock and maple, as well as the previous pine and spruce trees [31]. This progression of desired species creates discrepancies between time periods. With each time period including inconsistent species selection, successional progression for each treatment could be unique.

Logging practices have also changed with technology over the course of time; increasing the rate at which the disturbance was applied. This creates a discrepancy between early logged sites and more recently logged sites [32]. Given the life history of Algonquin tree species, the difference between the logging rates in early and late logging sites is negligible in the case of localities [31]. However, for a regional scale, the ability to create a more widespread disturbance, at a higher rate, will affect the measured outcome as the disturbance will affect most localities.

This study demonstrates that tree diversity in Algonquin Provincial Park can be predicted by the intermediate disturbance hypothesis, with time since logging as the measure of disturbance. Logging in Algonquin thus produces comparable patterns on species diversity as other human or naturally induced disturbances $[11,16,17,18]$. This study shows the necessity to continue to study the effects of human disturbances on diversity as the rate of species extinctions continues to increase globally $[1,2,3]$. It is, however, more complicated than just eliminating humancaused disturbances. Our results indicate the importance of determining the exact relationship between disturbance and diversity, since human-caused disturbances could have positive effects, depending on the rates or intensity of that disturbance. The next step would be to determine whether there are important differences between the relationships between human-caused disturbances and diversity versus natural disturbances, such as fire regimes, in these mixed forests of Algonquin. This will provide a solid background for managing the ecological integrity of this important ecosystem.

\section{METHODS}

\section{Selecting the areas to represent treatments and control}

We selected seven areas based on the time since logging, in approximately 30 year increments between 1860 and 2006. We based these times since logging on the availability and accessibility of sites. Time was used to gauge the level of disturbance; an intermediate amount of time since logging should correspond to high diversity. All seven sites bordered HWY \#60 in Ontario, Canada, and were representative of mixed forests. Data was collected between August 12 and August 18, 2009. Sites were named according to their proximity to major lakes or landmarks along HWY $\# 60$. The undisturbed site, dated as 1860 , will be further referred to as Brewer Lake. The six disturbed sites include: Big Pines; logged 1890, Booth's Rock; logged 1920, Sasajewun Lake; logged 1940; Sunday Lake; logged 1970, Rock Lake; logged 1979, and Wildlife Research Station hydro corridor; logged 2006.

\section{Data collection design at each site}

At each of the seven sites, three $10 \mathrm{~m} \times 10 \mathrm{~m}$ plots were marked out using flagging tape and a compass; we began at a selected point, marked the direction of travel on the compass and followed this direction for $10 \mathrm{~m}$. The compass was then rotated $90^{\circ}$ and we travelled $10 \mathrm{~m}$ in that direction. This was done for all four sides to ensure each plot was $100 \mathrm{~m}^{2}$. Flagging tape was used to mark the perimeter of the plot. Number of species and number of individuals per species present were tabulated using a counter, and recorded manually, for a total of twenty-one plots. Juvenile trees were excluded from the study since they do not reproduce (trees shorter than one metre). Trees touching the flag tape or whose main foliage or other large part entered the plots were included in the count.

\section{Additional data collection for local to regional scale study}

Three areas: Brewer Lake, Booth's Rock and the Wildlife Research Station (WRS) served as representatives of the earliest, intermediate and latest times since logging. 
Diversity data for two additional plots in each of these areas were measured. The first additional plot measured $20 \mathrm{~m} \mathrm{x}$ $20 \mathrm{~m}$, and the second one $40 \mathrm{~m} \times 40 \mathrm{~m}$; resulting in six additional plots to estimate the general effect of increased sampling area on species diversity and richness.

\section{Data manipulation, management and statistics}

We calculated species richness and diversity for all seven sites in the study and plotted them against year. To formally test for IDH, we fitted a second degree polynomial model with time since logging and its squared transformation as the predictor variables for each dependent variable. If the IDH predicts species richness patterns, the quadratic coefficient will be significant in the polynomial regression. Since we did not have enough replicates to perform a similar test for the larger sampling plots, we performed a visual check of the larger plots compared to the smaller ones.

To test whether the species present in the plots with maximal richness are a combination of pioneer and climax species, we performed a Redundancy Analysis (RDA) [24], with tree abundances as the dependent matrix, and time since logging as the quantitative predictor variable. This RDA allows us to visualize the species composition changes as time since logging decreases. Sites from an intermediate time since logging site should have a mix of species from both the earliest and latest logged sites. RDA is the multivariate extension of a multiple regression that determines the overall effects of potentially several predictor variables on a matrix of dependent variables [24]. If community composition at intermediate disturbances is different from the other disturbance levels, this would provide evidence for the regional model of IDH.

\section{ACKNOWLEDGEMENTS}

This project was undertaken as part of the Field Ecology course $\left(\mathrm{BIOL}^{*} 4410\right)$ with the University of Guelph during the summer of 2009. We would like to thank the people at the Wildlife Research Station for all their help, and the employees at the Algonquin Park Visitor's centre. We would especially like to thank Ron Toser and his son for their help in identifying the year that sites were last logged, and Dr. Andrew MacDougall for his insightful comments on the manuscript.

\section{REFERENCES}

1. Saunders, D.A., H.J. Hobbs, C.R. Margules. 1991. Biological consequences of Ecosystem Fragmentation: a review. Conservation Biology 5 (1): 18-27.

2. Debinski D.M. and R.D. Holt. 2000. A survey and overview of habitat fragmentation experiments. Conservation Biology 14, 342-355.
3. Strahler A.H, and O.W. Archibold. 2008. Physical Geography. Hoboken, NY: John Wiley \& Sons, Inc.

4. Cain M.L., W.D. Bowman and S.D. Hacker. Ecology. Sinauer Associates, Inc., Sunderland MA 2008.

5. Chapin F.S., E.S. Zavaleta, V.T. Eviner, R.L. Naylor, P.M. Vitousek, H.L. Reynolds, D.U. Hooper, S. Lavorel, O.E. Sala, S.E. Hobbie, M.C. Mack and S. Diaz. 2000. Consequences of changing biodiversity. Nature. 405, 234-242.

6. Sala O.E., F.S. Chapin III, J.J. Armesto, E. Berlow, J. Bloomfield, R.Dirzo, E. Huber-Sanwald, L.F. Huenneke, R.B. Jackson, A. Kinzig, R.Leemans, D.M.Lodge, H.A.Mooney, M.Oesterheld, N.LeRoy Poff, M.T.Sykes, B.H.Walker, M.Walker and D.H.Wall. 2000. Global biodiversity scenarios for the year 2100 . Science $\mathbf{2 8 7}$ : 1770-1774.

7. Connell J.H. 1978. Diversity in tropical rain forests and coral reefs. Science, New Series 199(4335):1302-1310.

8. Mackey R.L. and D.J. Currie. 2001. The diversitydisturbance relationship: is it generally strong and peaked? Ecology 82(12): 3479-3492.

9. Campbell N.A. and J.B. Reece. Biology $7^{\text {th }}$ edition. Pearson Benjamin Cummings, New York 2005.

10. Molles Jr. M.C. Ecology: Concepts and applications $3^{\text {rd }}$. McGraw-Hill, New York 2005.

11. Bongers F., L. Poorter, W.D. Hawthorne and D. Sheil. 2009. The intermediate disturbance hypothesis applies to tropical forests, but disturbance contributes little to tree diversity. Ecology Letters 12: 798-805.

12. Chase J.M. and M.A. Leibold. Ecological niches: linking classical and contemporary approaches. The University of Chicago Press, Chicago and London 2003.

13. D'Odorico P., F. Laio, L. Ridolfi and M.T. Lerdau. 2008. Biodiversity enhancement induced by environmental noise. Journal of Theoretical Biology 225: 332-337.

14. Denslow J.S. 1995. Disturbance and diversity in tropical rain forests: the density effect. Ecological applications 5(4): 962-968.

15. Wilkinson D.M. 1999. The disturbing history of intermediate disturbance. Oikos 84: 145-147.

16. Molino J. and D. Sabatier. 2001. Tree diversity in tropical rain forests: a validation of the intermediate disturbance hypothesis. Science 294: 1702-1704.

17. Sheil D. 2001. Long-term observations of rain forest succession, tree diversity and responses to disturbance. Plant Ecology 155: 183-199.

18. Sheil D. and D.F.R.P. Burslem. 2003. Disturbing hypotheses in tropical forests. Trends in Ecology and Evolution 18(1): 18-26.

19. Roxburgh S.H., K. Shea and J.B. Wilson. 2004. The intermediate disturbance hypothesis: patch dynamics and mechanisms of species coexistence. Ecology 85(2): 359-371. 
20. Martin N.D. 1959. An analysis of forest succession in Algonquin Park, Ontario. Ecological Monographs 29(3): 187-218.

21. Strickland D. Trees in Algonquin provincial park. The Friends of Algonquin Park, Whitney, ON, Canada 2006.

22. Provincial Parks and Conservation Reserves Act. 2006. Available [ONLINE] at: http://www.elaws.gov.on.ca/html/statutes/english/elaws_statutes_06p 12 _e. htm\#BK0

23. Canada National Parks Act. 2011. Available [ONLINE] at: http://laws.justice.gc.ca/PDF/Statute/N/N-14.01.pdf

24. Legendre P. and L. Legendre. Numerical Ecology. Elsevier Science, Amsterdam, The Netherlands 1998.

25. Purves W.K., D. Sadava, G.H. Orians and H.C. Heller. Life the science of biology. Sinauer Associates Inc. Sunderland, MA, USA 2004.

26. Guo, Q. 2003. Temporal species richness-biomass relationships along successional gradients. Journal of Vegetation Science 14: 121-128.
27. West D.C., H.H. Shugart and D.B. Botkin. Forest succession: concepts and application. Springer-Verlag, New York 1980.

28. Connell J.H. and R.O. Slatyer. 1977. Mechanisms of succession in natural communities and their role in community stability and organization. The American Naturalist 111: 1119-1144.

29. Greene D.F. and E.A. Johnson. 1996. Wind dispersal of seeds from a forest into a clearing. Ecology 77(2): 595609.

30. Duncan S.R. and C.A. Chapman. 1999. Seed dispersal and potential forest succession in abandoned agriculture in tropical Africa. Ecological Applications 9(3): 9981008.

31. Algonquin Forestry Authority (AFA). 2007. Available [ONLINE] at: http://www.algonquinforestry.on.ca.

32. Shae K., S.H. Roxburgh and E.S.J. Rauschert. 2004. Moving from pattern to process: coexistence mechanisms under intermediate disturbance regimes. Ecology Letters 7: 491-508. 